\title{
RELATIONSHIP OF ELECTRICAL RESISTANCE OF VAGINAL MUCUS DURING OESTRUS WITH POST-AI PREGNANCY IN COWS
}

\author{
M. Ahmed ${ }^{1}$, M. K. Chowdhury ${ }^{2}$, M. M. Rahman ${ }^{1}$, J. Bhattacharjee ${ }^{1}$ and M. M. U. Bhuiyan ${ }^{{ }^{*}}$ \\ ${ }^{1}$ Department of Surgery and Obstetrics, Faculty of Veterinary Science, Bangladesh Agricultural University, \\ Mymensingh-2202, Bangladesh; ${ }^{2}$ Department of Livestock Services, Krishi Khamar Sarak, Farmgate, Dhaka \\ 1215, Bangladesh.
}

\begin{abstract}
Accurate detection of oestrus is a common problem for farmers to do AI timely resulting in conception failure in cows. The objective of the present study was to know the electrical resistance of vaginal mucus (ERVM) during oestrus to determine the best time of AI for improvement of conception in cattle. A total of 28 cows were inseminated with frozen thawed semen after detection of ERVM with Draminski estrus detector at Kendua Upazila Livestock Office under Netrakona district of Bangladesh. Pregnancy was diagnosed by per rectal palpation of genital tract 8-10 weeks after insemination. The mean ERVM in pregnant cows was $208.5 \pm 31.2 \Omega(163.3$ to $263.3 \Omega$ ) and the ERVM in non-pregnant cows was $214.4 \pm 36.6 \Omega$ (153.3 to $280.0 \Omega$ ). Moreover, the pregnancy rate was higher in cows $(80.0$ to $83.3 \%)$ when ERVM during oestrus varied from 150 to $220 \Omega$ than that of 221 to $280 \Omega$ counterpart (36.4\%). The difference in pregnancy rates between groups was significant $(\mathrm{P}<0.05)$. The present study indicates that Dramniski electrical heat detector may be used for prediction of time for AI in cows of Bangladesh. Up to $220 \Omega$ ERVM during oestrus is better for higher conception rate than that of more than $220 \Omega$ counterparts. Further studies with high number of inseminated cows should be conducted before wide application of this electrical heat detector under field conditions in Bangladesh.
\end{abstract}

Keywords: cows, electrical heat detector, electrical resistance of vaginal mucus (ERVM)

\section{INTRODUCTION}

The total number of cattle population in Bangladesh is satisfactory with respect to size of the country. However, the yield of the most of our cattle is low resulting in deficit in milk and meat production in the country. Artificial insemination (AI) has been in use for long time globally to reduce the occurrence of sexually transmitted diseases among cattle and to increase the use of genetically superior sires to improve yield of the herd (Dransfield et al., 1998). However, proper oestrus detection and timely insemination are very important for success of any AI programme. Detection of oestrus in cows may often be difficult due to short periods of standing estrus, silent estrus, changing nutritional regimens, environmental temperatures and oestrus onset during the late night to early morning hours. There is a report that about $40 \%$ cows remained undetected when they were in oestrus in small holding farms in Bangladesh (Shamsuddin et al., 2001). Moreover, many difficulties were encountered in detecting oestrus by visual observation alone, especially in large herds (Pelissier, 1972). During the past decades, numerous studies have reported change in electrical resistance of vaginal mucus might be associated with oestrus in cows (Kitwood et al., 1993; Hulsure et al., 1995). The electrical resistance tends to decline markedly at oestrus and cows inseminated with low ERVM had higher pregnancy rate than those inseminated when ERVM was high (Leidl and Stolla, 1976).

Considering the above mentioned facts, scientists are trying to develop various aids for detection of oestrus in cows. The electrical oestrus detector is one of the aids which monitor changes in ERVM during oestrus. The onset of estrous is characterized in part by increasing levels of oestrogen. It is likely that as the levels of oestrogen rise, it may increase the activity of a metabolic pathway which may produce adrenocorticotropic hormone and aldosterone. One effect of these products is that they increase the levels of $\mathrm{NaCl}$ (sodium chloride) in the vaginal mucus. As a result, $\mathrm{NaCl}$ itself decreases ERVM during oestrus than other times (Fehring et al., 1997). The low electrical resistance might be an indication for proper time of insemination and such electrical

*Corresponding e-mail address: mmubhuiyan@gmail.com Copyright@2017 Bangladesh Society for Veterinary Medicine 


\section{Ahmed and others}

resistance can be easily determined by commercial electrical heat detector device where proper heat detection may be compromised. By this time, this type of commercial electrical heat detector for cows has been used elsewhere (Patil and Pawshe, 2011). However, very few reports are available on using electrical heat detector in farm animals of Bangladesh (Hasan, 2013; Malakar, 2014). Moreover, no study has been conducted in cows to determine the optimum value of ERVM during oestrus on pregnancy rate in Bangladesh. The objective of the present study was to know the ERVM during oestrus to determine the best time of AI for improvement of conception in cattle.

\section{MATERIALS AND METHODS}

\section{Description of animals and data collection}

The study was carried out at the Kendua Upazila Livestock Office under Netrakona district during the period from January to November 2016. The cows brought for AI in the livestock office were used for collecting data and investigation.

A total of 28 animals were included in this study of which 6 were heifers and 22 were cows of 1 to 6 parities. Seventeen animals were cross bred between non-descript local and Friesian, and 11 animals were local breed. The age of the animals varied from 1.5 to 10 years, the body weight varied from 120 to $220 \mathrm{Kg}$, the body condition score varied from 2.5 to 4.5 and the rectal temperature varied from 99 to $102^{\circ} \mathrm{F}$. The number of services given to the animals varied from 1 to 3 , the interval between oestrus and AI varied from 7 to 18 hours. All data on animals were collected by either examination of animals or by interviewing the farmers and recorded by using questionnaire. Before selection, the animals were examined per rectum to confirm that they were not pregnant. The animals that were not in oestrus and had clinical uterine infection were not selected for the study.

\section{Description of farm management}

The animals were tied in the barn at night and sometimes grazed at day time. The animals were fed mostly on straw, cut and carry green grasses and small amount of concentrate mixture consisting of wheat bran, rice polish and molasses. The animals were given concentrate feed two times daily. All cows were hand milked keeping the calves at feet of the cows and calves suckled several times after milking. The animals were vaccinated against commonly occurring infectious diseases and dewormed routinely.

\section{Detection of estrus and determination of ERVM}

Oestrus of cows and heifers was detected by the farmers on the basis of clinical manifestation of oestrus signs. To determine the values of ERVM, Draminski estrus detector (Draminski Electronics in Agriculture, 17 Owocowa, 10-860 Olsztyn, Poland) was used. Briefly, after restraining the cows, the vulva of the animals were cleaned with mild antiseptic solution and dried with clean cloth. The Draminski estrus detector was prepared after cleaning the probe with mild antiseptic. The probe was then inserted through vulva and reached up to the cervix. The value of the ERVM was determined as per instruction of the manufacturer and the average value of three consecutive measurements was recorded immediately prior to insemination.

\section{Artificial insemination and pregnancy diagnosis}

All the animals were inseminated after taking reading by the oestrus detector. The animals were inseminated by using frozen thawed semen supplied by Department of Livestock Services (DLS), Bangladesh. The insemination was performed by the trained inseminator of Kendua Upazila Livestock Office, Netrakona. All farmers were asked for detection of oestrus 20 to 22 days after insemination. The cows detected in oestrus by the farmers after 20 to 22 days of insemination were regarded as non-pregnant. The cows which were not detected in oestrus by the farmers after 20 to 22 days of insemination were further monitored for pregnancy diagnosis. The pregnancy was confirmed by per rectal palpation of genital tract 8 to 10 weeks after insemination. 


\section{Experimental approaches and statistical analysis:}

To determine the best time of insemination on the basis of ERVM during oestrus, the animals were divided into three groups such as 150 to 180,181 to 220 and 221 to $280 \Omega$ resistance showing groups. The collected data on ERVM were entered into Excel 2010 datasheet. The data were arranged and, mean and standard deviation were calculated. ANOVA was performed by using SPSS (ERVMsion 13) to determine the presence of significant difference in pregnancy rates among three groups of cows with respect to electrical resistance. The difference in pregnancy rate was considered significant when the $\mathrm{P}$ value was less than 0.05 .

\section{RESULTS AND DISCUSSION}

A total of 28 cows were inseminated after detection of oestrus with Draminski estrus detector. The ERVM in pregnant and non-pregnant cows is shown in Figure 1 and Table 1. The ERVM in pregnant cows was $199.8 \pm$ $29.4 \Omega$ (range from 163.3 to $263.3 \Omega$ ) and the ERVM in non-pregnant cows was $227.7 \pm 34.5 \Omega$ (range from 153.3 to $280.0 \Omega)$.

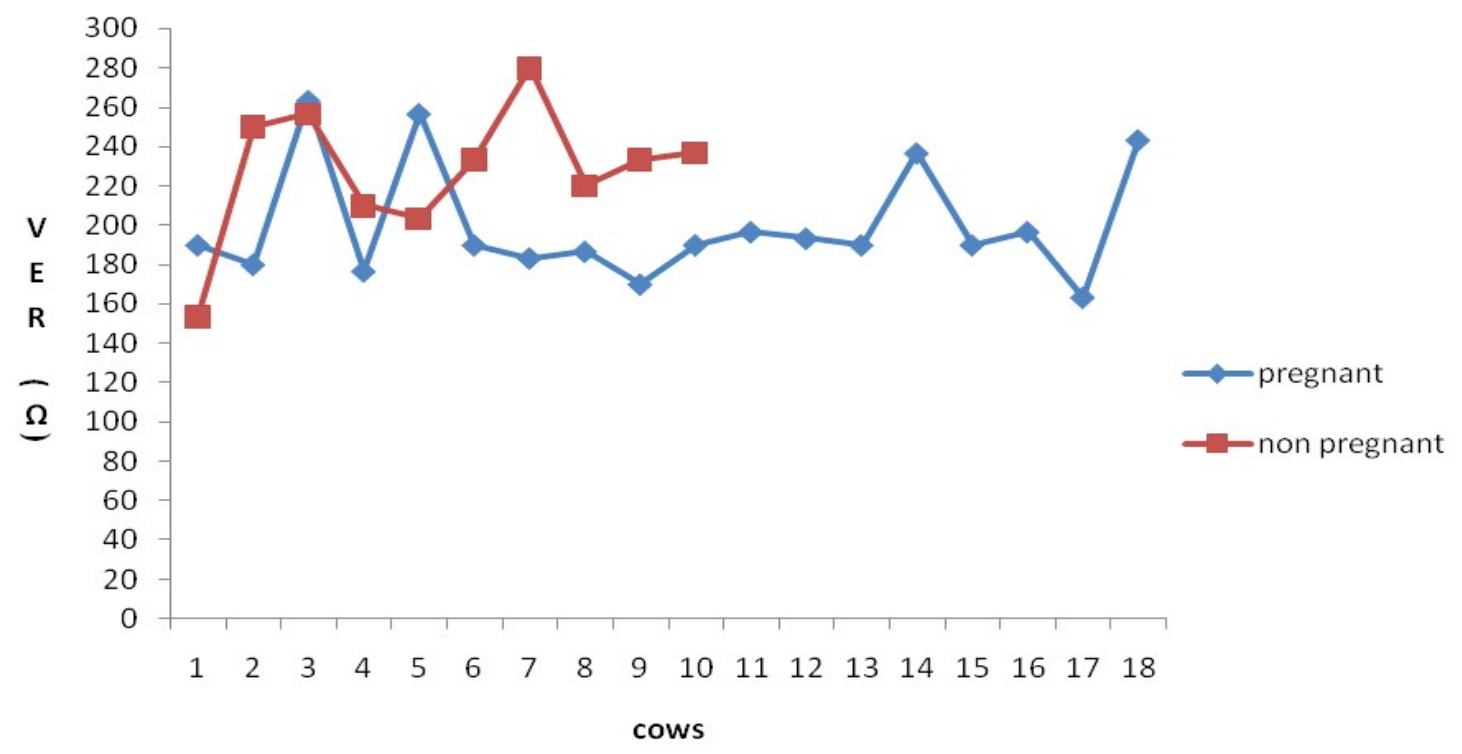

Figure 1. The ERVM before insemination in different pregnant and non-pregnant cows

Table 1. The ERVM recorded before insemination in pregnant and non-pregnant cows

\begin{tabular}{cccc}
\hline Pregnancy status of cows & Number of cows & Range of ERVM $(\Omega)$ & Mean \pm SD of ERVM $(\Omega)$ \\
\hline Pregnant & 18 & 163.3 to 263.3 & $199.8 \pm 29.4$ \\
\hline Non-pregnant & 10 & 153.3 to 280.0 & $227.7 \pm 34.5$
\end{tabular}

$\mathrm{ERVM}=$ Electrical resistance of vaginal mucus.

The pregnancy rate in cows with respect to different ERVM during oestrus is shown in Table 2. The pregnancy rate was higher in cows (80.0 to 83.3\%) when ERVM during oestrus varied from 150 to $220 \Omega$ than that of 221 to $280 \Omega$ counterpart (36.4\%). The difference in pregnancy rates between groups was significant $(\mathrm{P}<0.05)$. 
Table 2. Pregnancy rates in relation to the values of ERVM at the time of insemination

\begin{tabular}{cccc}
\hline ERVM $(\Omega)$ & No. of cows inseminated & No. of cows pregnant & Pregnancy rate $(\%)$ \\
\hline $150-180$ & 5 & 4 & $80.0^{\mathrm{a}}$ \\
$181-220$ & 12 & 10 & $83.3^{\mathrm{a}}$ \\
$221-280$ & 11 & 4 & $36.4^{\mathrm{b}}$ \\
\hline
\end{tabular}

ERVM $=$ Electrical resistance of vaginal mucus.

${ }^{\mathrm{a}, \mathrm{b}}$ The values in the same column with superscript differed significantly from each other $(\mathrm{p}<0.05)$

Accurate detection of oestrus is a common problem for farmers to submit for AI timely resulting in low conception rate in cows. Conception failure causes the farmers to become frustrated for rearing cows. Therefore, a series of studies like synchronization, ovsynch and milk progesterone test have been conducted to solve the problem of insemination without detecting oestrus (Pursley et al., 1997; Samad et al., 2004). For long time, scientists are trying to develop various aids for detection of oestrus in cows. The electrical oestrus detector is one of the aids which monitor changes in electrical resistance of the vaginal mucus during oestrus. The onset of oestrous is characterized in part by increasing levels of oestrogen followed by production of adrenocorticotropic hormone and aldosterone resulting in increased level of $\mathrm{NaCl}$ in the vaginal mucosa. As a result, $\mathrm{NaCl}$ itself decreases electrical resistance of vaginal mucosa during oestrus than other times (Fehring, 1997). Therefore, low ERVM might be an indication for proper time of insemination and such electrical resistance can easily be determined by commercial electrical heat detector device where proper heat detection may be compromised. Considering this, a commercial Dramniski electrical oestrus detector was used in this study.

In the present study, the ERVM in pregnant cows was numerically higher than that of non pregnant cows and the pregnancy rate was significantly higher in cows when ERVM during oestrus was up to $220 \Omega$ than that of $>220$ $\Omega$ counterparts. The present finding is in agreement with earlier study where cows inseminated with low electrical resistance had higher pregnancy rate than those inseminated when electrical resistance was high (Leidl and Stolla, 1976). Moreover, Jotanovic et al. (2011) reported higher pregnancy rate in cows when those were inseminated with higher ERVM.

Oestrus in cows is always manifested with the discharge of clear mucus. This mucus helps to transport spermatozoa through the genital tract after insemination. Along with changes in ovaries and uterine mucosa, cyclical changes also occur in cervix to facilitate sperm transport by relaxing cervix and secretion of cervical mucus (Yousef, 1981). Secretion of mucus from the cervical canal glands fills cervix during oestrus followed by passing through vagina and vulva. Vaginal mucus except epithelial cells and substances necessary for the survival of spermatozoa usually contains electrolytes (salts of sodium, magnesium, calcium and other cations) which determine its electrochemical reaction. The presence of electrolytes leads to ionization of oestrous mucus and affects its electrical conductivity. Based on these characteristics of oestrous mucus, methods for determining the ERVM has been developed as a method for detecting the optimum time for insemination (Rorrie et al., 2002). Accordingly, during oestrus, declined ERVM has been reported elsewhere (Tasal et al., 2005). However, some pathological conditions of the reproductive tract, such as vaginitis and cervicitis may also cause to obtain low value of ERVM similar to oestrous period.

Nevertheless, the present study indicates that the electrical heat detector can be a suitable aid for determination of time for AI in cows followed by obtaining satisfactory conception rate. Accordingly, McCaughey and Patterson (1981) found a relation between the value of ERVM with the level of progesterone in milk and observed signs of oestrus. Contrasting to the earlier findings, Foote et al. (1985) described determination of ERVM as insufficiently reliable in large farms conditions to predict time for AI. Additionally, Zuluaga et al. (2007) reported that determination of ERVM is not reliable in detecting the optimum time for insemination after induction and synchronization of ovulation in cows. Elving et al. (1983) also reported that the method of measuring ERVM is not effective for oestrus detection in cows.

It is concluded that Draminski electrical heat detector can be used for proper detection of time of AI in cows. However, further studies with high number of inseminated cows should be conducted before wide application of this electrical heat detector under field conditions in Bangladesh. 


\section{ACKNOWLEDGEMENTS}

We are grateful to Professor Dr. Nasrin Sultana Juyena, Department of Surgery and Obstetrics, Faculty of Veterinary Science, Bangladesh Agricultural University, Mymensingh for providing the Draminski electrical heat detector.

\section{REFERENCES}

1. Dransfield MBG, Nebel RL, Pearson RE and Warnick LD (1998). Timing of insemination for dairy cows identified in estrus by a telemetric estrus detection system. Journal of Dairy Science 81: 1874-1882.

2. Elving L, Pieterse MC and Vernooy AM (1983). A prospective study of the usefulness of an intravaginal electrical resistance meter for estrus detection in cattle. Tijdschrift Voor Diergeneeskunde 108: 85-89.

3. Fehring RJ (1997). A comparison of the ovulation method with the CUE ovulation predictor in determining fertile period. Journal of American Academy of Nurse Practitioners 8: 461-466.

4. Firk R, Stemer E, Junge W and Krister J (2002). Automation of estrus detection in dairy cows. Livestock Production Science 75: 219-232.

5. Foote RH, Oltenacu EAB, Mellinger J, Scott NR and Marshall RA (1979). Pregnancy rate in dairy cows inseminated on the basis of electronic probe measurements. Journal of Dairy Science 62: 69-73.

6. Hasan MM (2013). Study on vaginal electrical impedance in female water buffaloes during post partum period. MS in Theriogenology Thesis, Department of Surgery and Obstetrics, Bangladesh Agricultural University, Mymensingh.

7. Hulsure MS, Pargaonkar DR and Bakshi SA (1995). Studies on use of electronic probe estrone to detect heat in cows and to monitor optimum time for insemination. Indian Journal of Reproduction 16: 107-108.

8. Jotanovic S, Sahinovic R, Stancic I, Migavic R, Vekic M and Savic D (2011). Relationship between electrical resistance of vaginal mucus in the moment of insemination and cows' pregnancy rate. The Serbian Journal of Agricultural Sciences 60: 105-109.

9. Kitwood SE, Phillips CJC and Wiese M (1993). Use of a vaginal mucus impedance meter to detect oestrus in the cow. Theriogenology 40: 559-569.

10. Leidl W and Stolla R (1976). Measurement of electric resistance of the vaginal mucus as an aid for heat detection. Animal Reproduction Science 5: 259-273.

11. Malakar S (2014). Study of vaginal electrical impedance with heat detector in cows during post partum period. MS in Theriogenology Thesis, Department of Surgery and Obstetrics, Faculty of Veterinary Science, Bangladesh Agricultural University, Mymensingh, Bangladesh.

12. McCaughey WJ and Patterson AD (1981). Vaginal electrical resistance in cows: 2. Relationship to milk progesterone concentrations during the reproductive cycle. Veterinary Research Communication 5: 77-84.

13. Patil SR and Pawshe CH (2011). Vaginal electrical resistance during different phase of oestrus cycle in cows and heifers. Indian Journal of Animal Reproduction 32: 58-60.

14. Pelissier CL (1972). Herd breeding problems and their consequences. Journal of Dairy Science 55: 385.

15. Pursley JR, Wiltbank MC, Stevension JS, Ottobre JS, Garverick HA and Anderson LL (1997). Pregnancy rates per artificial insemination for cows and heifers inseminated at asynchronized ovulation or synchronized oestrus. Journal of Dairy Science 80: 295-300.

16. Rorie RW, Bilby TR and Lester TD (2002). Application of electronic oestrus detection technologies to reproductive management of cattle. Theriogenology 57: 137-148.

17. Samad HA, Ahmad N, Bengmen and Rehman NU (2004). Use of milk progesterone assay for monitoring oestrus and early pregnancy in Nili-Ravi buffaloes. Pakistan Veterinary Journal 24: 121-124.

18. Shamsuddin M, Bhuiyan MMU, Sikder TK, Sugulle AH, Chanda PK, Alam MGS and Galloway D (2001). Constraints limiting the efficiency of artificial insemination of cattle in Bangladesh. Radioimmunoassay and related techniques to improve artificial insemination programs for cattle reared under tropical and sub-tropical conditions. Proceeding of Final Research Coordination Meeting organized by the joint FAO/IAEA Division of Nuclear Techniques in Food and Agriculture and held in Uppsala, Sweden, 10-14 May, 1999. 9-28.

19. Yousef A (1981). Note on the biochemical aspects of bovine cervical mucus. The Indian Journal of Animal Sciences 51: 1082-1085.

20. Tasal I, Ataman MB, Aksoy M, Kaya A, Karaea F and Tekel T (2005). Estimation of early pregnancy by electrical resistance values of vaginal mucosa in cows and heifers. Reveu de Medicine Veterinarian 156: 91-94.

21. Zuluaga JF, Saldarriaga JP, Cooper DA, Cartmill JA and Williams GL (2007). Evaluation of vaginal electrical resistance as an indicator of follicular maturity and suitability for timed artificial insemination in beef cows subjected to a synchronization of ovulation protocol. Animal Reproduction Science 109: 17-26. 